\title{
Towards a simple design procedure for dynamically embedded plate anchors
}

\author{
C. D. O’LOUGHLIN*, A. P. BLAKE* and C. GAUDIN*
}

\begin{abstract}
Dynamically embedded plate anchors (DEPLAs) are a promising option for anchoring floating facilities in deep water, as relative to current technology such as suction caissons, the anchor will be much smaller and less expensive to install. This paper considers data from the final stage of an experimental campaign that has been undertaken as a preliminary step towards qualification of the DEPLA at full scale. The experiments involved field testing of a 1:4.5 reduced-scale DEPLA in approximately $50 \mathrm{~m}$ water depth at a site off the west coast of Scotland. Measurements in the tests included accelerations during free fall in water and embedment in soil, and pullout resistance as the DEPLA was loaded to failure and subsequently retrieved to the deck of the installation vessel. The acceleration data are used in the paper to explore the suitability of strain rate formulations for scaling the undrained shear strength to values appropriate for dynamic penetration, and to demonstrate the potential for a dynamic penetration model to predict the final anchor embedment depth. The paper finishes by summarising output from the embedment model in a simple design chart that can be used to scale a DEPLA for a given mooring line load.
\end{abstract}

KEYWORDS: anchors \& anchorages; offshore engineering; strain

\section{INTRODUCTION}

The advent of floating liquid natural gas facilities will bring an associated increase in mooring line loads, requiring either an upscale in current anchor technology such as the suction caisson, or more technically efficient and cost-effective anchor concepts. Dynamically installed anchors such as the torpedo pile are attractive in this regard owing to the minimal installation times, although their relatively low capacity-to-weight ratio means that they must be significantly upscaled to provide the required capacity (O'Loughlin et al., 2015). This has obvious cost and operational implications. Vertically loaded plate anchors - which may be installed by dragging, driving, or using a suction caisson - are geotechnically efficient, offering a high capacity-to-weight ratio, but can be difficult to install, particularly if they are drag embedded.

A relatively new anchor concept, referred to as the dynamically embedded plate anchor (DEPLA), combines the installation advantages of dynamically installed anchors with the capacity advantages of vertically loaded plate anchors. The DEPLA comprises a removable central shaft or 'follower' and a set of four flukes arranged on a cylindrical sleeve and connected to the follower with a shear pin. The DEPLA is installed in a similar manner to other dynamically installed anchors, by releasing the anchor from a height above the seafloor, chosen such that the anchor will impact the seabed at a velocity approaching its terminal velocity and subsequently self-bury in the ocean floor sediments. After the DEPLA has come to rest in the seabed, the follower retriever line is tensioned. This causes the shear pin to part (if not already broken during impact), allowing the follower to be retrieved for the next installation, but leaving the anchor flukes vertically embedded in the seabed. These

Manuscript received 18 September 2015; revised manuscript accepted 16 March 2016. Published online ahead of print 27 April 2016.

Discussion on this paper closes on 1 February 2017, for further details see p. ii.

* Centre for Offshore Foundation Systems, The University of Western Australia, Crawley, WA, Perth, Australia. embedded anchor flukes constitute the load-bearing element as a plate anchor. When sufficient load develops in the mooring line, the plate rotates or 'keys' to an orientation that is approximately perpendicular to the direction of loading at the padeye, allowing full bearing resistance of the plate to be mobilised. The DEPLA and its installation and keying processes are summarised in Fig. 1.

The holding capacity of a plate anchor such as the DEPLA is relatively straightforward for a given shear strength profile and a known embedment depth as it requires only the selection of an appropriate capacity factor. These are now well established for a wide range of plate anchor geometries (e.g. Martin \& Randolph, 2001; Merifield et al., 2003; Song et al., 2008; Wang et al., 2010; Yu et al., 2011), and more specifically for the DEPLA (Wang \& O'Loughlin, 2014). However, predicting this final plate anchor embedment is challenging, as it first requires an assessment of the final DEPLA penetration depth after free fall in water, and second requires an assessment of the extent of embedment loss of the plate anchor during keying. The loss in embedment during keying has been investigated experimentally for suction embedded plate anchors (e.g. Gaudin et al., 2006, 2009; O'Loughlin et al., 2006; Wang et al., 2011; Cassidy et al., 2012; Yang et al., 2012), and the results of these studies are relevant to the DEPLA (O'Loughlin et al., 2014a). Predicting the final embedment of the DEPLA after free fall is complicated, as the high penetration velocities associated with the dynamic installation process require interpretative frameworks that are capable of scaling the soil strength from nominally undrained values to values associated with the very high strain rates in the soil, and that account for hydrodynamic effects, notably the drag resistance that dominates at shallow embedment in soft soils.

The DEPLA is attractive for facilities with higher mooring loads, as relative to current technology such as suction caissons, the anchor will be much smaller and less expensive to install (O'Loughlin et al., 2015). An experimental campaign, including proof-of-concept centrifuge tests (O'Loughlin et al., 2014a) and reduced-scale field trials (Blake \& O'Loughlin, 2015; Blake et al., 2015), has been recently undertaken as a preliminary step towards qualification of the anchor at full 


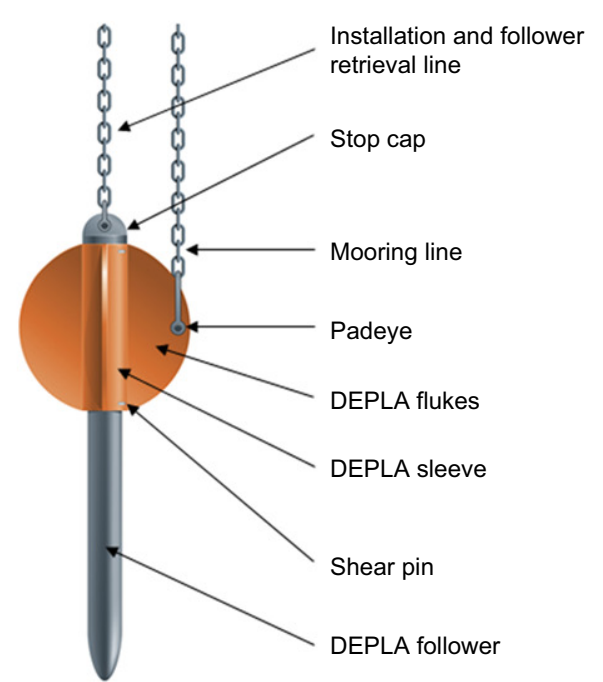

(a)

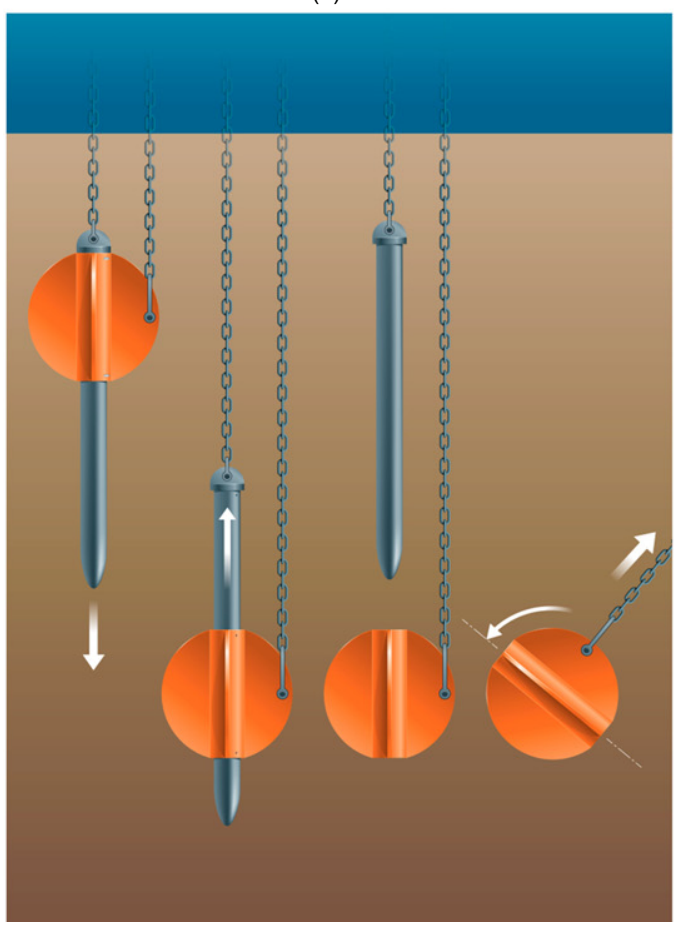

(c)

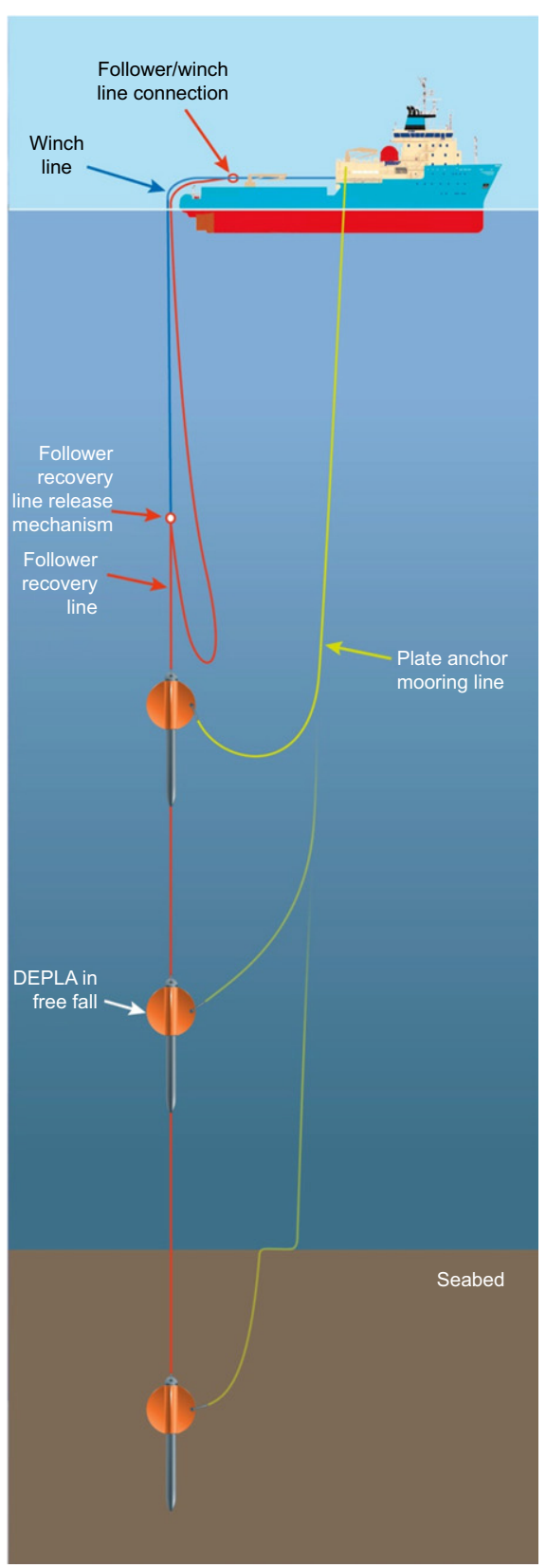

(b)

Fig. 1. Dynamically embedded plate anchor: (a) annotated schematic diagram; (b) installation procedure; (c) post-installation keying and capacity mobilisation

scale. This paper considers data from the final phase of reduced-scale field trials, which focused on DEPLA installation and capacity mobilisation at a soft seabed site off the west coast of Scotland. Measurements in the trials include accelerations during free fall in water and embedment in soil, and pullout resistance as the DEPLA was loaded to failure and subsequently retrieved to the deck of the installation vessel. These data, together with previously reported centrifuge data (O'Loughlin et al., 2014a) and field data from an onshore site (Blake \& O'Loughlin, 2015; Blake et al., 2015), are considered to investigate the merit of frameworks for predicting anchor embedment depth after dynamic installation and the subsequent anchor capacity.

\section{FIELD TRIALS}

\section{Test sites and soil properties}

The field tests were conducted at the Firth of Clyde, which is located off the west coast of Scotland between the mainland and the Isle of Cumbrae. At the test location the water depth is typically $50 \mathrm{~m}$.

Figure 2 summarises index properties for the seabed sediments at Firth of Clyde over the $4.8 \mathrm{~m}$ sampling depth. The soil is very soft, with moisture contents in the range $40-90 \%$ (close to the liquid limit). Consistency limits plot above or on the A-line on the Casagrande plasticity chart, indicating a clay of intermediate to high plasticity. The unit weight is in the range $13-18 \mathrm{kN} / \mathrm{m}^{3}$, increasing with depth. Fig. 3 shows profiles of undrained shear strength, $s_{\mathrm{u}}$, with depth derived from piezocone and piezoball tests, and calibrated using lab shear vane data and fall cone tests, to give piezocone bearing factors $N_{\mathrm{kt}}=17.8\left(5 \mathrm{~cm}^{2}\right.$ cone $)$ and $N_{\mathrm{kt}}=16.9\left(10 \mathrm{~cm}^{2}\right.$ cone $)$, and piezoball bearing factors $N_{\text {ball }}=11 \cdot 5\left(50 \mathrm{~cm}^{2}\right.$ ball $)$ and $N_{\text {ball }}=12 \cdot 2\left(100 \mathrm{~cm}^{2}\right.$ ball $)$, similar to that suggested by Low et al. (2010). The $s_{\mathrm{u}}$ profile is best idealised as $s_{\mathrm{u}}=2+2 \cdot 8 z(\mathrm{kPa})$ over the upper $z=5 \mathrm{~m}$ of the penetration profile, which is the depth of interest for the DEPLA tests. The piezoball tests included cyclic 

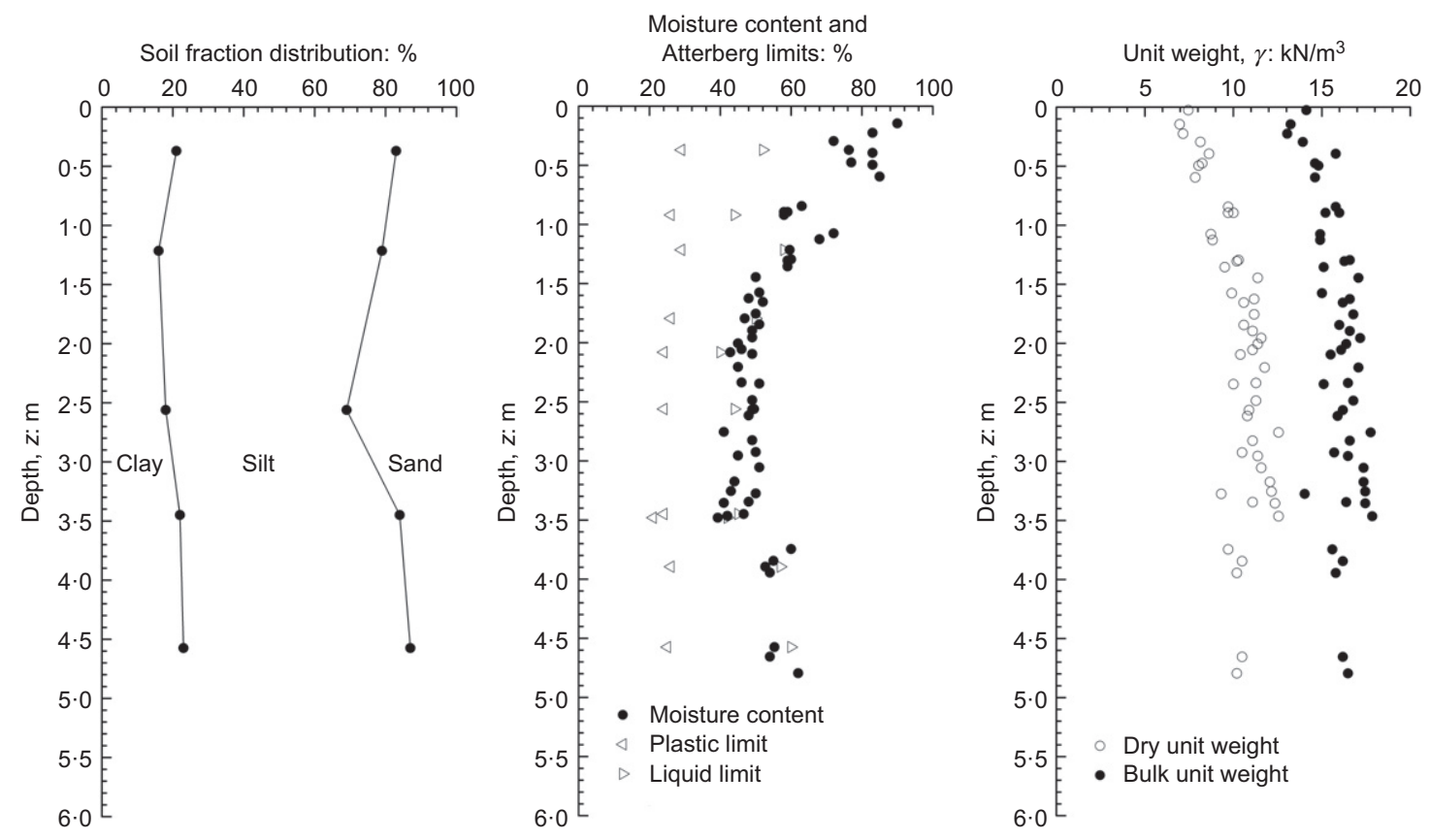

Fig. 2. Index properties at the anchor trial locations in Firth of Clyde

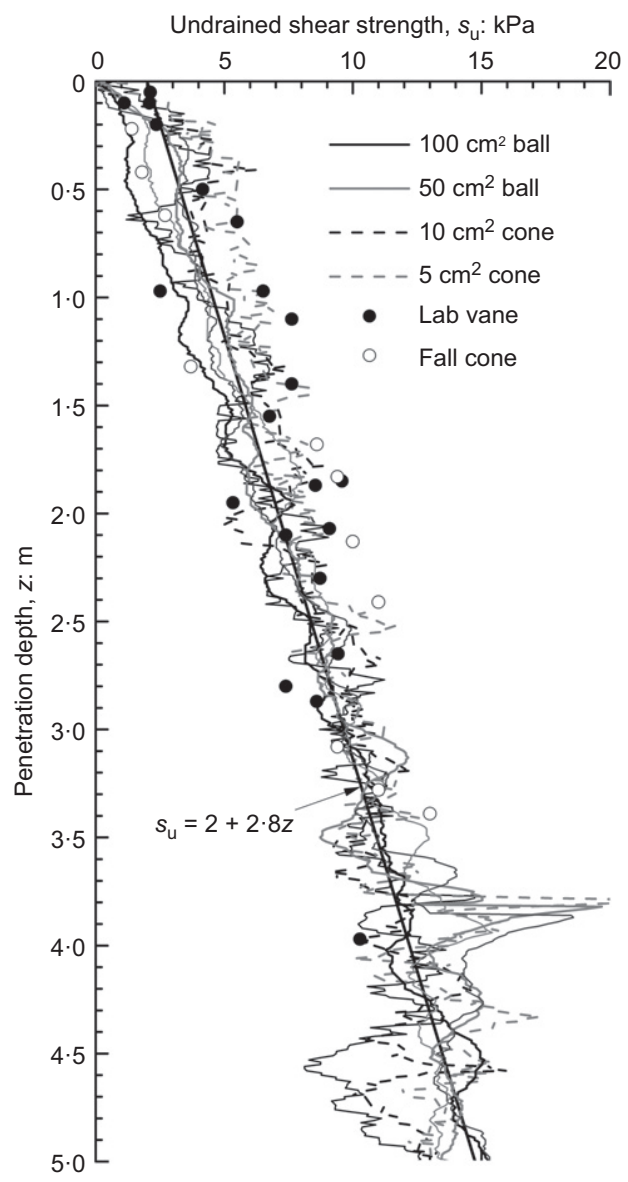

Fig. 3. Undrained shear strength profile at the anchor trial locations in Firth of Clyde

remoulding episodes, where the piezoball was moved vertically by $\pm 0.5 \mathrm{~m}(4 \cdot 4$ to $6 \cdot 25$ piezoball diameters $)$ at depths of $2.3 \mathrm{~m}$ and $4.3 \mathrm{~m}$. The degradation in soil strength is plotted for each cycle number (following the cycle numbering notation suggested by Randolph et al. (2007))

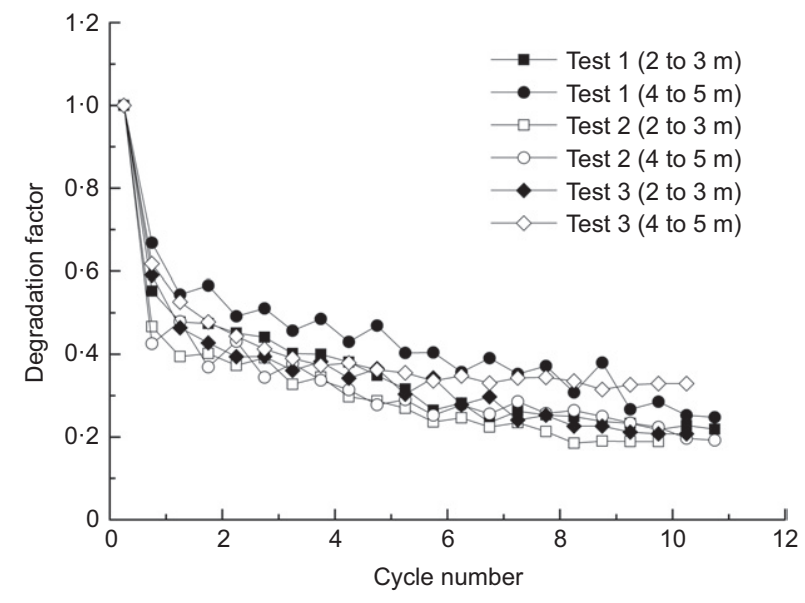

Fig. 4. Degradation of undrained shear strength with cycle number during piezoball cyclic remoulding tests

in Fig. 4 and indicates that the sensitivity of the soil is in the range $S_{\mathrm{t}}=2 \cdot 4-4 \cdot 6$.

\section{Instrumented reduced-scale DEPLA}

The DEPLA was modelled at a reduced scale of $1: 4 \cdot 5$, based on a full-scale anchor with a follower length of $9 \mathrm{~m}$ (appropriate for typical mobile drilling operations). It was manufactured from mild steel with a total mass, $m=388.6 \mathrm{~kg}$, of which the follower mass, $m_{\mathrm{f}}=297 \mathrm{~kg}$ and the plate mass, $m_{\mathrm{p}}=91.6 \mathrm{~kg}$. A schematic diagram of the model DEPLA, including the notation used for the main dimensions, is shown in Fig. 5, with the main dimensions of the anchor summarised in Table 1. The onshore trials reported by Blake \& O'Loughlin (2015) and Blake et al. (2015) tested this same 1:4.5 scale anchor and two smaller anchors at scales of 1:7·2 and 1:12. As these data are also considered throughout the paper their dimensions and masses are also listed in Table 1. Dyneema SK75 rope with a diameter of $12 \mathrm{~mm}$ was used to install the DEPLA (and to retrieve the follower) and as the mooring line connected to one of the DEPLA flukes. 


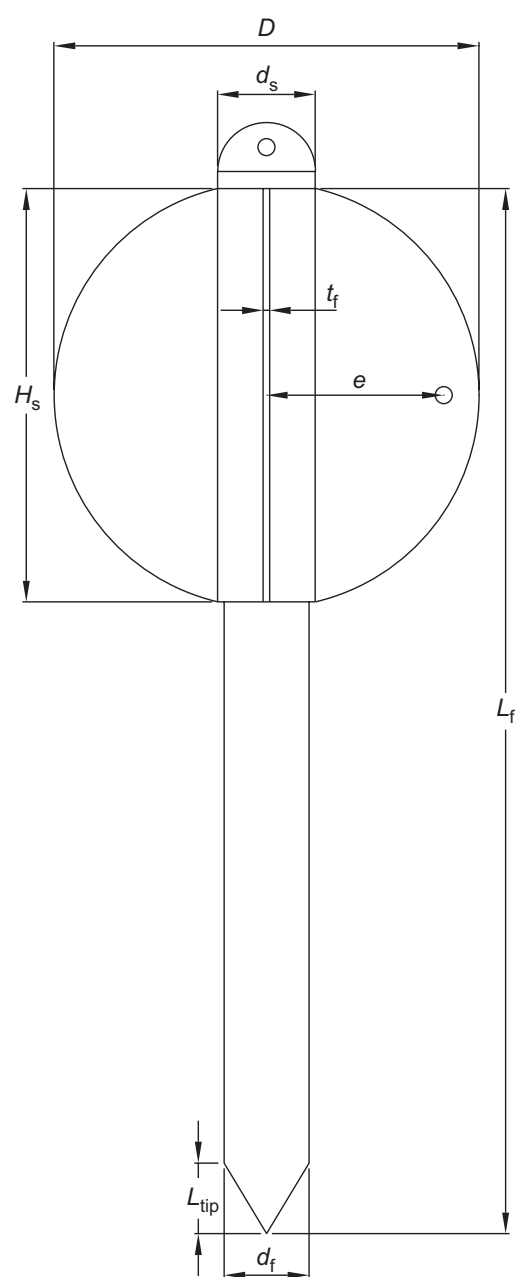

Fig. 5. DEPLA schematic representation and notation

Table 1. Reduced-scale DEPLA anchors used in the field trials

\begin{tabular}{l|c|c|c}
\hline & $\begin{array}{c}1: 12 \\
\text { scale* }\end{array}$ & $\begin{array}{c}1: 7 \cdot 2 \\
\text { scale* }\end{array}$ & $\begin{array}{c}1: 4 \cdot 5 \\
\text { scale } \dagger\end{array}$ \\
\hline Follower length, $L_{\mathrm{f}}: \mathrm{mm}$ & 750 & 1250 & 2000 \\
Tip length, $L_{\mathrm{tip}}: \mathrm{mm}$ & 50 & $83 \cdot 3$ & $133 \cdot 3$ \\
Follower diameter, $d_{\mathrm{f}}: \mathrm{mm}$ & 60 & 100 & 160 \\
Sleeve diameter, $d_{\mathrm{s}}: \mathrm{mm}$ & 71 & 115 & 184 \\
Sleeve height, $H_{\mathrm{s}}: \mathrm{mm}$ & 290 & 487 & 779 \\
Plate diameter, $D: \mathrm{mm}$ & 300 & 500 & 800 \\
Fluke thickness, $t_{\mathrm{f}}: \mathrm{mm}$ & $4 \cdot 5$ & $6 \cdot 25$ & 10 \\
Padeye eccentricity, $e: \mathrm{mm}$ & 125 & $212 \cdot 5$ & 348 \\
Eccentricity ratio, $e / D$ & $0 \cdot 42$ & $0 \cdot 43$ & $0 \cdot 44$ \\
Follower mass, $m_{\mathrm{f}}: \mathrm{kg}$ & $14 \cdot 8$ & $73 \cdot 7$ & 297 \\
Plate (flukes) mass, $m_{\mathrm{p}}: \mathrm{kg}$ & $5 \cdot 5$ & $22 \cdot 3$ & $91 \cdot 6$ \\
Total mass, $m: \mathrm{kg}$ & $20 \cdot 3$ & 96 & $388 \cdot 6$ \\
\hline
\end{tabular}

*Previous studies (Blake \& O’Loughlin, 2015; Blake et al., 2015). $\dagger$ Present study.

The DEPLA follower was solid, except for a $185 \mathrm{~mm}$ long, $42 \mathrm{~mm}$ dia. void at the top of the follower, which housed a custom-design, low-cost, six-degree-of-freedom inertial measurement unit (IMU), described in detail by Blake et al. (2016). The IMU includes a 16-bit three-component microelectromechanical system (MEMS) rate gyroscope (ITG 3200) and a 13-bit three-axis MEMS accelerometer (ADXL 345). The gyroscope had a resolution of $0.07 \%$ with a measurement range of $+/-2000 \%$ s. The accelerometer had a resolution of $0.04 \mathrm{~m} / \mathrm{s}^{2}$ with a measurement range of $+/-16 \mathrm{~g}$. Data were logged by an mbed microcontroller with

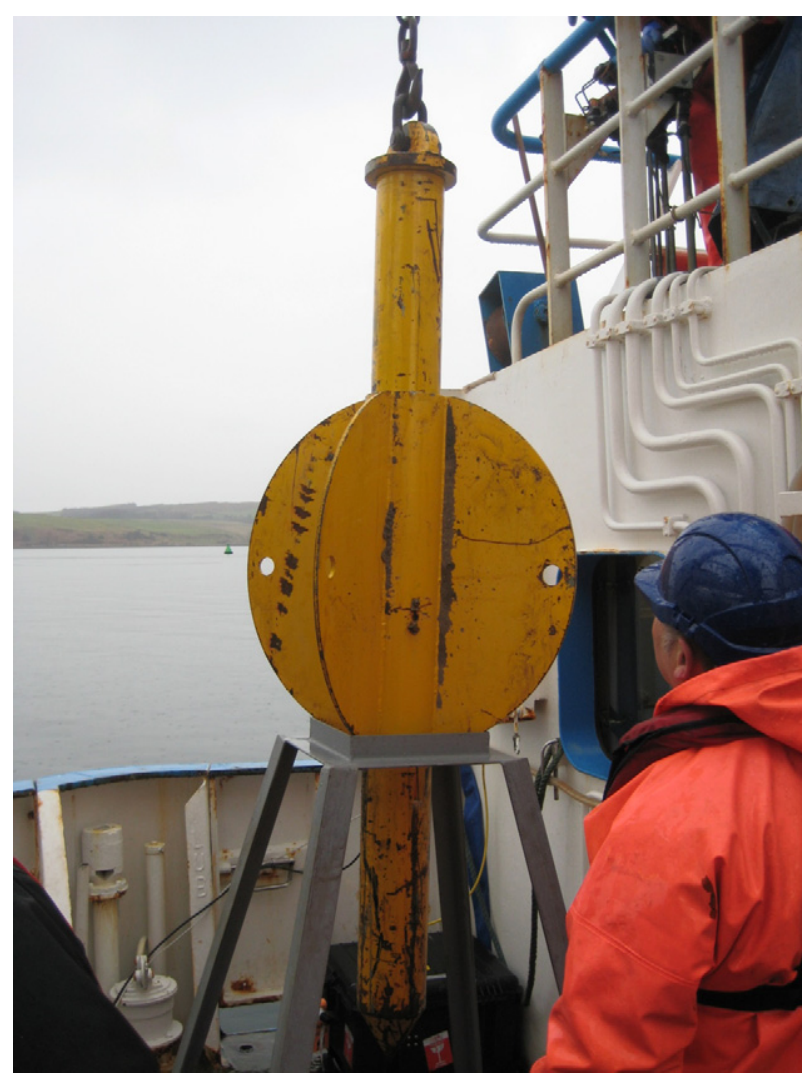

Fig. 6. Assembling the DEPLA on the deck of the RV Aora in preparation for installation

an ARM processor to a $2 \mathrm{~GB}$ secure digital (SD) card at $400 \mathrm{~Hz}$. Internal batteries were capable of powering the logger for up to $4 \mathrm{~h}$. The IMU was contained in a watertight aluminium tube $185 \mathrm{~mm}$ long and $42 \mathrm{~mm}$ in diameter.

\section{Test procedure}

The field trials were conducted from the $R V$ Aora, a $22 \mathrm{~m}$ research and survey vessel in the Firth of Clyde, equipped with several winches and an $8 \mathrm{t}$ crane. The testing procedure involved the following stages.

(a) The IMU was powered up and secured in the follower.

(b) The DEPLA was assembled on the deck of the RVAora by lowering the follower through the flukes and connecting the follower and flukes with a shear pin (see Fig. 6).

(c) The anchor was then lowered in the water to the required drop height and then released by opening a quick-release shackle connecting the follower retrieval line to the crane, allowing the anchor to free fall and penetrate the seabed.

(d) The anchor tip embedment depth, $z_{\mathrm{e}, \text { tip }}$, was measured by sending a remotely operated vehicle to the seabed to inspect markings on the follower retrieval line (see Fig. 7).

(e) Following dynamic installation, the load cell was connected in series with the winch cable and follower retrieval line, and the winch was used to extract the follower at approximately $30 \mathrm{~mm} / \mathrm{s}$. Movement of the follower relative to the flukes causes the shear pins to break (if they did not break on impact with the soil), allowing the follower to be retrieved to the vessel deck.

( $f$ ) The plate anchor mooring line was then connected to the winch cable and a draw wire sensor was connected 
in parallel with the winch cable to allow for monitoring of the line displacement. The plate was loaded vertically using the winch, which caused the mooring line to move at $30 \mathrm{~mm} / \mathrm{s}$ (as for the follower retrieval) and effected the keying and capacity mobilisation of the DEPLA plate. This was continued until the DEPLA plate was retrieved from the seabed and recovered on the vessel deck. Approximately $1 \mathrm{~h}$ elapsed between installation and plate loading, which corresponds to a dimensionless reconsolidation time, $T=c_{\mathrm{h}} t_{\mathrm{c}} / D^{2}=0.006$ (where $c_{\mathrm{h}}$ is the horizontal coefficient of consolidation $\sim 30 \mathrm{~m}^{2} /$ year, $t_{\mathrm{c}}$ is the reconsolidation time $=1 \mathrm{~h}$ and $D$ is the plate diameter $=0.8 \mathrm{~m}$ ) such that minimal reconsolidation and hence strength regain occurred after installation.

\section{RESULTS AND DISCUSSION}

The experimental programme at Firth of Clyde included 13 tests, as summarised in Table 2. These results are discussed in further detail in the following sections.

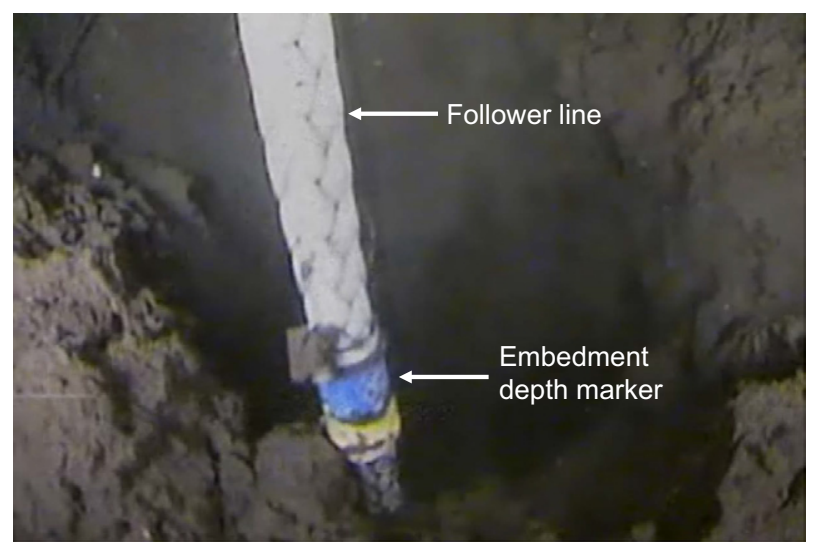

Fig. 7. An ROV video still showing the DEPLA installation site. These observations were primarily intended to ensure no gross error in the embedment depth established from the anchor instrumentation, but also provided evidence that the hole created by the passage of the anchor remained open
Impact velocity and embedment

Anchor impact velocities achieved in the field tests were in the range $v_{\mathrm{i}}=5.6-12.9 \mathrm{~m} / \mathrm{s}$, corresponding to anchor release heights of $2 \cdot 3-2 \cdot 5 \mathrm{~m}$. The upper end of this velocity range is close to the anchor's terminal velocity (Blake \& O'Loughlin, 2015), although for drop heights greater than that required to reach terminal velocity, the anchor eventually slows owing to the additional drag resistance mobilised by the anchor lines. Resulting anchor tip embedments were in the range $z_{\text {e,tip }}=2 \cdot 75-4 \cdot 01 \mathrm{~m}$ (up to two times the anchor length). Anchor tip embedments are shown on Fig. 8 and compared with results from onshore trials (Blake \& O'Loughlin, 2015) conducted in a lake underlain by clay with a strength gradient of about $1 \mathrm{kPa} / \mathrm{m}$ (i.e. almost three times lower than that at the Firth of Clyde). Fig. 8 shows a clear dependence of impact velocity on embedment depth, with similar dependence for both datasets. Although the stronger soil at the Firth of Clyde site reduces the embedment depth by about $50 \%$, as will be shown later in the paper the anchor capacity is not significantly affected.

As shown by O'Loughlin et al. (2013), comparisons of embedment trends between anchors of different geometries and mass, installed in seabeds with different strength profiles, can be simplified by considering the total energy of the anchor, defined as the sum of the kinetic and potential energy (relative to the final embedment depth) of the anchor as it impacts the soil

$$
E_{\text {total }}=\frac{1}{2} m v_{\mathrm{i}}^{2}+m^{\prime} \boldsymbol{g} z_{\mathrm{e}, \mathrm{tip}}
$$

where $m^{\prime}$ is the effective mass of the anchor (submerged in soil). The data considered here are plotted in non-dimensional form on Fig. 9, with tip embedments expressed as $z_{\mathrm{e}, \mathrm{tip}} / d_{\mathrm{eff}}$ (where the effective anchor diameter, $d_{\text {eff }}=\left(4 A_{\mathrm{f}} / \pi\right)^{0 \cdot 5}$, accounts for the total frontal area, $A_{\mathrm{f}}$, due to the anchor shaft and flukes) and total energy is expressed as $E_{\text {total }} / k d_{\text {eff }}^{4}$ (removing the influence of soil strength gradient, $k$ and anchor diameter). The current data are plotted together with previously reported DEPLA field and centrifuge data (O'Loughlin et al., 2014a; Blake \& O'Loughlin, 2015) and other available centrifuge and field data for dynamically installed anchors. The data form a relatively tight band that can be conservatively fitted by the following expression

Table 2. Summary of test results

\begin{tabular}{|c|c|c|c|c|c|c|c|c|}
\hline $\begin{array}{l}\text { Test } \\
\text { no. }\end{array}$ & $\begin{array}{l}\text { Anchor } \\
\text { release } \\
\text { height: } \mathrm{m}\end{array}$ & $\begin{array}{c}\text { Anchor impact } \\
\text { velocity, } \\
v_{\mathrm{i}}: \mathrm{m} / \mathrm{s}\end{array}$ & $\begin{array}{l}\text { Anchor tip } \\
\text { embedment, } \\
z_{\text {e,tip: }} \mathrm{m}\end{array}$ & $\begin{array}{c}\text { Anchor tip } \\
\text { travel distance, } \\
s: \mathrm{m}\end{array}$ & $\begin{array}{l}\text { Peak anchor } \\
\text { capacity, } \\
F_{\mathrm{v}, \mathrm{p}}: \mathrm{kN}\end{array}$ & $\begin{array}{c}\text { Final plate } \\
\text { embedment } \\
\text { depth, } z_{\text {e,plate }}: \mathrm{m}\end{array}$ & $\begin{array}{c}\text { Plate } \\
\text { embedment } \\
\text { ratio, } z_{\text {e,plate }} / D\end{array}$ & $\begin{array}{l}\text { Anchor } \\
\text { capacity } \\
\text { factor, } N_{\mathrm{c}}\end{array}$ \\
\hline 1 & $42 \cdot 508$ & $12 \cdot 9$ & $4 \cdot 010$ & $4 \cdot 19$ & $31 \cdot 2$ & $1 \cdot 589$ & 2 & $9 \cdot 4$ \\
\hline 2 & $40 \cdot 552$ & $12 \cdot 4$ & 3.685 & $3 \cdot 8$ & 32 & $1 \cdot 264$ & $1 \cdot 6$ & $11 \cdot 2$ \\
\hline 3 & $48 \cdot 426$ & $11 \cdot 5$ & $3 \cdot 292$ & $3 \cdot 46$ & $29 \cdot 5$ & 0.871 & $1 \cdot 1$ & $12 \cdot 9$ \\
\hline $4^{*}$ & $47 \cdot 223$ & $11 \cdot 4$ & $3 \cdot 504$ & $3 \cdot 76$ & - & - & - & - \\
\hline $5 \dagger$ & $46 \cdot 464$ & $12 \cdot 3$ & $3 \cdot 874$ & $4 \cdot 22$ & - & - & - & - \\
\hline $6 \%$ & $49 \cdot 3 \S$ & - & $3 \cdot 7 \|$ & - & $21 \cdot 9$ & $1 \cdot 279$ & $1 \cdot 6$ & $7 \cdot 6$ \\
\hline 7 & $47 \cdot 25$ & $11 \cdot 8$ & $3 \cdot 326$ & $3 \cdot 62$ & $25 \cdot 6$ & 0.905 & $1 \cdot 1$ & $10 \cdot 9$ \\
\hline 8 & $48 \cdot 797$ & $12 \cdot 1$ & $3 \cdot 386$ & $4 \cdot 15$ & $29 \cdot 9$ & 0.965 & $1 \cdot 2$ & $12 \cdot 3$ \\
\hline 9 & $47 \cdot 824$ & $11 \cdot 7$ & $3 \cdot 611$ & $3 \cdot 86$ & $23 \cdot 8$ & $1 \cdot 19$ & $1 \cdot 5$ & $8 \cdot 6$ \\
\hline 109 & $48 \cdot 472$ & $10 \cdot 8$ & $3 \cdot 3 \|$ & - & $20 \cdot 2$ & 0.879 & $1 \cdot 1$ & $9 \cdot 7$ \\
\hline $11 \%$ & $50 \S$ & - & $3 \cdot 7 \|$ & - & $29 \cdot 5$ & $1 \cdot 279$ & $1 \cdot 6$ & $10 \cdot 3$ \\
\hline 12 & $2 \cdot 259$ & $5 \cdot 6$ & $2 \cdot 754$ & $2 \cdot 77$ & $6 \cdot 9$ & 0.333 & $0 \cdot 4$ & $4 \cdot 2$ \\
\hline 13 & $17 \cdot 678$ & $10 \cdot 6$ & $3 \cdot 305$ & $3 \cdot 53$ & $21 \cdot 9$ & 0.884 & $1 \cdot 1$ & $9 \cdot 4$ \\
\hline
\end{tabular}

* No capacity measurements as ROV became entangled with mooring line; follower and plate retrieved together.

$\dagger$ No capacity measurements as data acquisition system failed.

\#No IMU data.

$\S$ Determined from RVAora's echo sounder measurements.

|Determined from ROV video capture.

ףIMU failed after impact with the seabed. 


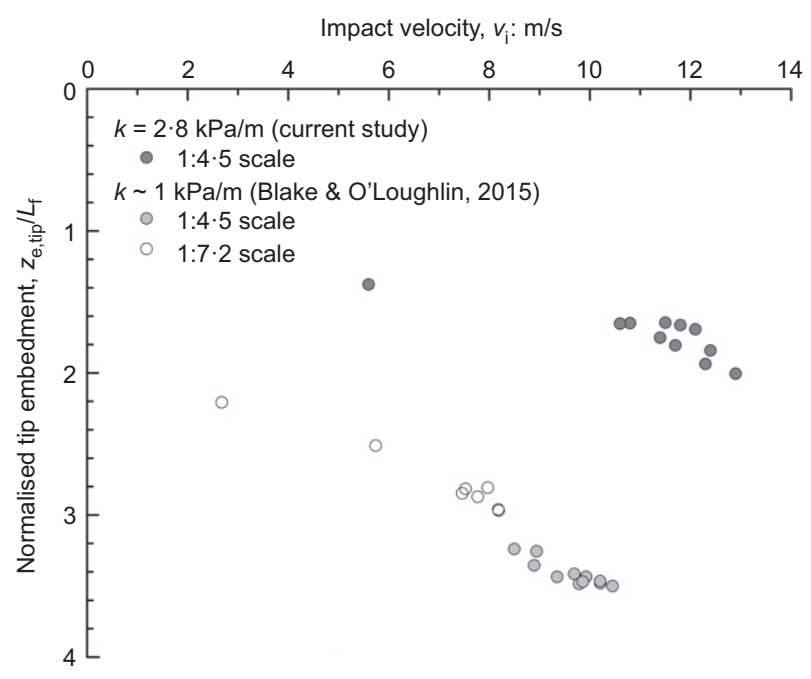

Fig. 8. Embedment trends for different scale DEPLAs in soils with different strength gradients

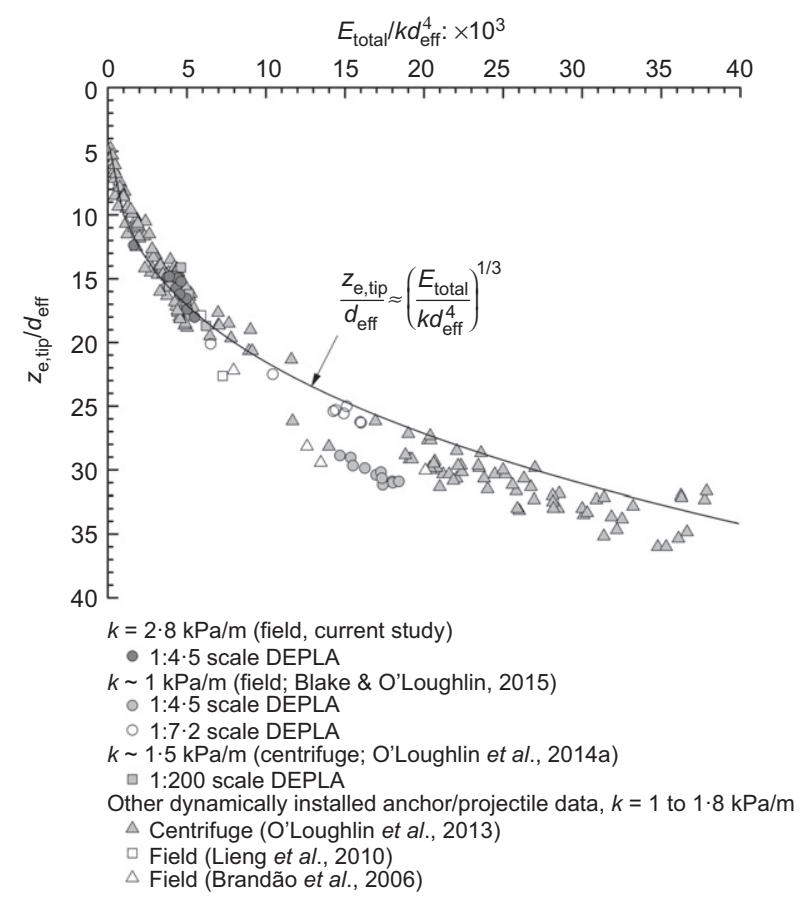

Fig. 9. Harmonising embedment trends through the use of total energy

suggested by O'Loughlin et al. (2013)

$$
\frac{z_{\mathrm{e}, \mathrm{tip}}}{d_{\mathrm{eff}}} \approx\left(\frac{E_{\mathrm{total}}}{k d_{\mathrm{eff}}^{4}}\right)^{1 / 3}
$$

As shown by O'Loughlin et al. (2014b), equation (2) has merit in obtaining a first-order approximation of the anchor scale required for a given mooring design. However, the normalisation has further benefits as demonstrated later in the paper.

\section{Plate anchor capacity}

After removing the DEPLA follower, the plate anchor mooring line was tensioned such that the DEPLA plate was vertically loaded. This loading causes the DEPLA to rotate in the soil, undergoing a loss of embedment in the process. This is shown clearly by Fig. 10, which plots the

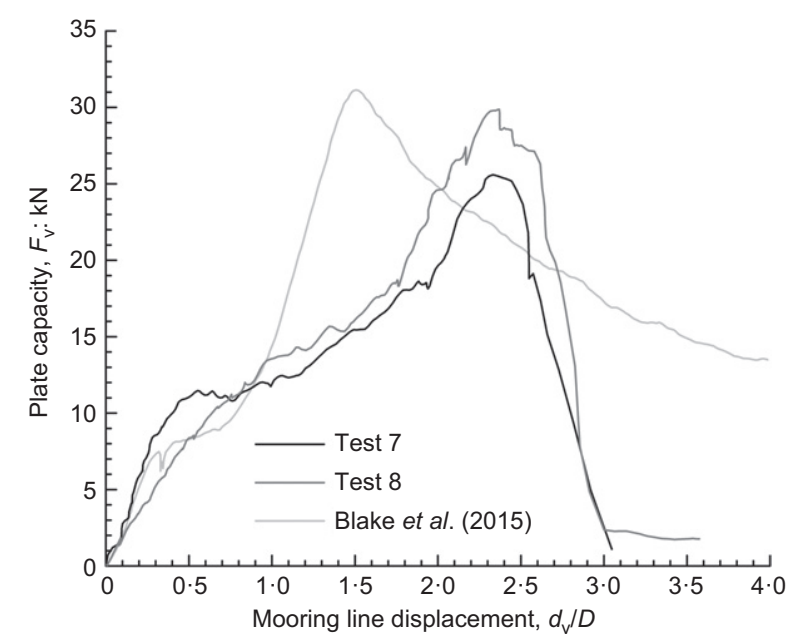

Fig. 10. Typical load-displacement responses during keying and pullout

mooring line displacement, $d_{\mathrm{v}}$, as a function of the plate capacity, $F_{\mathrm{v}}$. Also shown in Fig. 10 is an example response reported by Blake et al. (2015) from field trials conducted at an onshore site with $k=1 \mathrm{kPa} / \mathrm{m}$ using the same DEPLA scale and testing procedure. It is worth noting the similar capacity for both sites despite the much shallower embedment from the Firth of Clyde tests associated with the much higher strength gradient. This is because the capacity of dynamically installed anchors such as the DEPLA is governed by the soil strength at the final embedment depth. This will be higher in weaker soils and lower in stronger soils, but with approximately the same strength at the final plate embedment depth in either case.

Although in principle the loss in embedment may be established from the mooring line displacement (that was measured on the vessel deck), the elongation of the highmodulus polyethylene rope makes attempts to derive the plate displacement from the mooring line displacement erroneous and unreliable. This is more pronounced in Fig. 10 for the results from Firth of Clyde than for the onshore tests reported by Blake et al. (2015), as the water depth, and hence elongation of the rope, is much higher at the Firth of Clyde. However, the loss in embedment during keying has been extensively investigated for plate anchors (e.g. Gaudin et al., 2006, 2009; O'Loughlin et al., 2006; Song et al., 2009; Wang et al., 2011) and as shown by O'Loughlin et al. (2014a) the loss of embedment for a DEPLA is similar to that of a geometrically comparable plate, and can be calculated from

$$
\frac{\Delta z_{\mathrm{e}, \text { plate }}}{D}=\frac{0 \cdot 144}{\left[(e / D)(t / D)^{0.2}\right]^{1 \cdot 15}}
$$

Hence for the 1:4.5 scale DEPLA considered here, the loss in embedment for vertical loading is calculated to be $\Delta z_{\text {e,plate }} \sim 1 D$ (or $0.8 \mathrm{~m}$ ).

The DEPLA capacity may be expressed as an anchor capacity factor

$$
N_{\mathrm{c}}=\frac{F_{\mathrm{v}, \text { net }}}{A s_{\mathrm{u}, \mathrm{p}}}
$$

where $F_{\mathrm{v}, \text { net }}$ is the peak capacity $\left(F_{\mathrm{v}, \mathrm{p}}\right)$ minus the submerged weight of the plate anchor in soil, $A$ is the area of the plate and $s_{\mathrm{u}, \mathrm{p}}$ is the undrained shear strength at the estimated anchor embedment at peak capacity $\left(z_{\text {e,plate }}\right)$, accounting for the loss of embedment calculated using equation (3). For determination of $N_{\mathrm{c}}$ using equation (4) to be meaningful, it is 


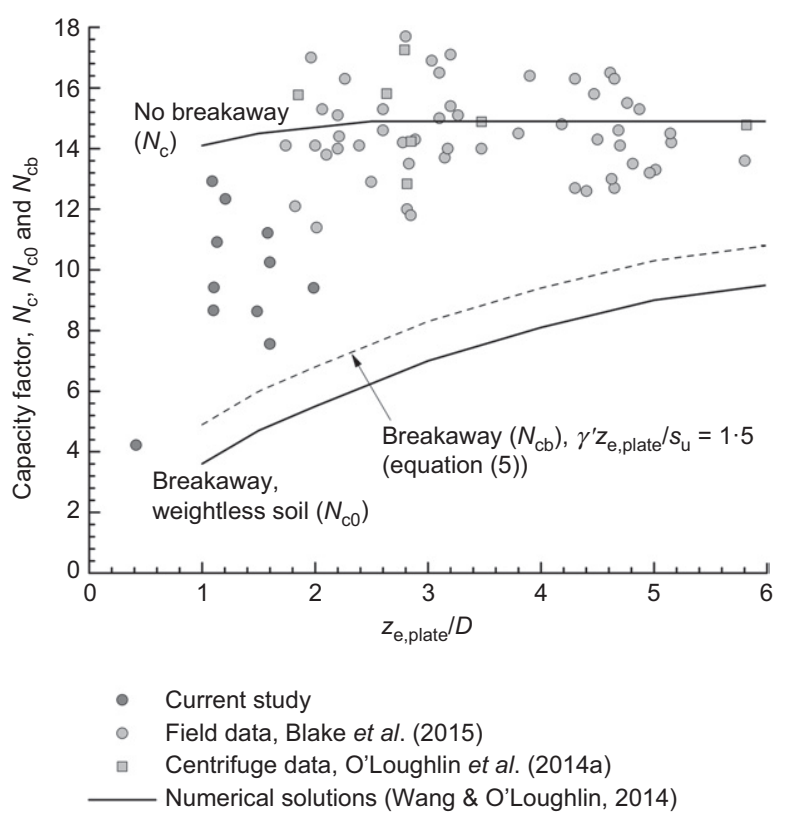

Fig. 11. Experimental and numerical anchor capacity factors

important that the strain rates associated with mobilisation of anchor capacity are comparable with those associated with measurement of $s_{\mathrm{u}}$. As described earlier, $s_{\mathrm{u}}$ was determined using $5 \mathrm{~cm}^{2}$ and $10 \mathrm{~cm}^{2}$ piezocones and $50 \mathrm{~cm}^{2}$ and $100 \mathrm{~cm}^{2}$ piezoballs, penetrated at the standard velocity, $v=20 \mathrm{~mm} / \mathrm{s}$. The average strain rate in the soil surrounding the penetrometers may therefore be approximated by $v / d=0 \cdot 18$ $0.25 \mathrm{~s}^{-1}$ for the piezoball and $v / d=0.56-0.79 \mathrm{~s}^{-1}$ for the piezocone, where $d$ is the diameter of the penetrometer. This overall range is comparable (within one order of magnitude) to $v / D=0.04 \mathrm{~s}^{-1}$ associated with loading of the DEPLA plate, such that experimental capacity factors may be determined without correction for strain rate effects.

$N_{\mathrm{c}}$ values for the Firth of Clyde trials are compared with other DEPLA centrifuge and field data in Fig. 11. Evidently the plate anchor embedments at peak capacity for the current data are much shallower than for the other field and centrifuge data, owing to the higher strength gradient at the Firth of Clyde. Capacity factors at these shallower embedments are also lower and occupy the wide range $N_{\mathrm{c}}=4 \cdot 2-12 \cdot 9$, compared with the typical range $N_{\mathrm{c}}=13-17$ at higher embedments. Wang \& O'Loughlin (2014) report DEPLA capacity factors derived from large deformation finite-element analyses for the case where soil tension is permitted at the base of the DEPLA plate (the so-called 'no breakaway' or 'attached' case) and for the case where soil tension is not permitted at the base of the plate (the so-called 'immediate breakaway' or 'vented' case). The results from these analyses are shown on Fig. 11 for a fully rough interface and $t_{\mathrm{f}} / D=0.027$ (rather than $t_{\mathrm{f}} / D=0.0125$ as used in the field tests). Experimentally derived DEPLA capacity factors at deep embedment (i.e. at $z_{\text {e,plate }} / D \geq 2 \cdot 5$ ) have a mean $N_{\mathrm{c}}=14 \cdot 6$, and as shown by Fig. 11, are in good agreement with the numerically derived deep no-breakaway capacity factor, $N_{\mathrm{c}}=14.9$. This limiting capacity factor is $13.7 \%$ greater than $N_{\mathrm{c}}=13 \cdot 11$, which is the exact solution for a deeply embedded infinitely thin rough circular plate (Martin \& Randolph, 2001), but only $3 \cdot 5 \%$ higher than the numerically derived $N_{\mathrm{c}}=14 \cdot 4$ for a deeply embedded rough circular plate with the same $t_{\mathrm{f}} / D=0.027$ (Wang \& O'Loughlin, 2014). This suggests that the failure mechanism for a deeply embedded circular plate and a deeply embedded circular DEPLA are broadly similar for the same plate thickness.
Several studies, including Das \& Singh (1994), Merifield et al. (2001, 2003), Wang et al. (2010) and Wang \& O'Loughlin (2014), have shown that the immediate breakaway capacity factor may be expressed as

$$
N_{\mathrm{cb}} \approx N_{\mathrm{c} 0}+\frac{\gamma^{\prime} z_{\mathrm{e}, \mathrm{plate}}}{s_{\mathrm{u}}} \leq N_{\mathrm{c}}
$$

where $N_{\mathrm{c} 0}$ is the immediate breakaway capacity factor in weightless soil (also shown in Fig. 11) and the dimensionless term, $\gamma^{\prime} z_{\mathrm{e} \text {,plate }} / s_{\mathrm{u}}$, captures the effect of overburden pressure. As discussed above, Fig. 11 shows that at deep embedment the experimentally derived capacity factors are in quite good agreement with the numerical no-breakaway values, whereas at shallower embedment (i.e. relating to the current dataset), the experimental capacity factors lie within the bounds of the soil weight adjusted immediate breakaway case (equation (5)) and the no-breakaway case. This observation appears reasonable, as at shallow embedment the failure mechanism extends to the soil surface, such that the gap formed during breakaway may fill with free water from above the mudline. In contrast, at deep embedment where the mechanism is localised, the formation of a gap beneath the DEPLA plate appears implausible as (for this rate of loading) water would not be able to fill the void. It is noteworthy that the experimental $N_{\mathrm{c}}$ values at shallow embedment for the current dataset are bounded by the numerical limits for immediate breakaway and no-breakaway, indicating that soil may completely or partially separate from the base of the plate at shallow embedments, or indeed may not separate at all. Conditions affecting the potential for occurrence of separation at the base of an anchor plate are considered in more detail by Han et al. (2016).

\section{EMBEDMENT DEPTH PREDICTION MODEL}

For typical offshore seabed deposits that are generally characterised by increasing strength with depth, reliability in the calculated anchor capacity first requires accurate prediction of the final anchor embedment depth after dynamic installation. In practice this can be confirmed by retrieving instrumentation of the type used in these tests from a 'pod' located on the exterior of the anchor (Lieng et al., 2010), but from a design perspective the final embedment depth needs to be pre-calculated so that the anchor can be scaled for the design mooring line load. As shown by Fig. 8, a first-order estimate of the embedment depth for a given anchor geometry, mass and seabed strength profile may be obtained using equation (2). However, this approach does not capture subtleties of the dynamic embedment process, including the influence of the variation in soil strength with strain (i.e. sensitivity) or strain rate, or geometrical aspects of the anchor that may influence the hydrodynamic response. A more rigorous approach would be to consider the forces acting on the anchor during dynamic embedment in soil and to calculate anchor velocities and displacements from the net acceleration associated with the resultant force. Several studies (e.g. True, 1976; Beard, 1981; Levacher, 1985; Aubeny \& Shi, 2006; Audibert et al., 2006; O'Loughlin et al., 2004, 2009, 2013) have adopted such an approach, with variations on the inclusion and formulation of the various forces acting on the anchor (or projectile) during penetration. More recently, Blake \& O'Loughlin (2015) have shown that it is more appropriate to consider force components acting in the direction of anchor motion, accounting for any anchor tilt that may occur before or during penetration in the soil. This is possible with the IMU measurements, which may be interpreted to consider anchor displacement in the direction of motion (rather than anchor penetration depth), as the displacements and velocities are calculated from the resultant anchor acceleration (Blake et al., 
2016). Consideration of the forces acting on the DEPLA during embedment in soil leads to a governing equation of

$$
\left(m+m_{\mathrm{a}}\right) \frac{\mathrm{d}^{2} s}{\mathrm{~d} t^{2}}=W_{\mathrm{s}}-F_{\mathrm{b}}-R_{\mathrm{f}}\left(F_{\text {frict }}+F_{\text {bear }}\right)-F_{\mathrm{d}}
$$

where $m$ is the anchor mass, $s$ is the distance travelled by the anchor along its trajectory (as distinct from depth, $z$ ), $t$ is time, $W_{\mathrm{s}}$ is the submerged anchor weight (in water), $F_{\mathrm{b}}$ is the buoyant weight of the displaced soil, $R_{\mathrm{f}}$ is a shear strain rate function, $F_{\text {bear }}$ is the bearing resistance, $F_{\text {frict }}$ is the frictional resistance and $F_{\mathrm{d}}$ is drag resistance. The added mass, $m_{\mathrm{a}}$, in equation (6) is the 'added' mass of the soil that is accelerated with the anchor. However, for slender bodies such as the DEPLA, $m_{\mathrm{a}}$ is negligible and can be taken as zero (Beard, 1981; Shelton et al., 2011). Frictional and bearing resistances are formulated as

$$
\begin{aligned}
& F_{\text {frict }}=\alpha s_{\mathrm{u}} A \\
& F_{\text {bear }}=N s_{\mathrm{u}} A
\end{aligned}
$$

where $\alpha$ is the interface friction ratio (of limiting shear stress to undrained shear strength), $N$ is the bearing capacity factor for the projectile tip or fluke and $s_{\mathrm{u}}$ is the undrained shear strength averaged over the contact area, $A$.

The inclusion of $F_{\mathrm{d}}$ in equation (6) may appear controversial, as this term is typically associated with a fluid mechanics framework for Newtonian materials. However, it is also justified for the (non-Newtonian) very soft fluidised soil typically encountered at the surface of the seabed, and has been shown to be important for assessing loading from a submarine slide runout on a pipeline (Boukpeti et al., 2012; Randolph \& White, 2012; Sahdi et al., 2014). O'Loughlin et al. (2013) and Blake \& O'Loughlin (2015) further showed that drag is the dominant resistance acting on a dynamically installed anchor in normally consolidated clay during initial embedment and typically to about $30 \%$ of the penetration. Drag resistance is formulated as

$$
F_{\mathrm{d}}=\frac{1}{2} C_{\mathrm{d}} \rho_{\mathrm{s}} A_{\mathrm{f}} v^{2}
$$

where $C_{\mathrm{d}}$ is the drag coefficient of the anchor, $\rho_{\mathrm{s}}$ is the density of the soil, $A_{\mathrm{f}}$ is the frontal area of the anchor and $v$ is the resultant velocity of the anchor (and hence line). Omitted from equation (9) is the drag resistance that acts on the lines. This should be considered during free fall in water, and indeed $C_{\mathrm{d}}=0.7$ as proposed by Blake \& O'Loughlin (2015) (and used here) was based on interpretation of free-fall measurements that considered frictional drag resistance on the DEPLA lines. However, the inclusion of drag resistance on the lines is not considered during embedment in soil as: (a) calculated frictional drag resistance on the lines is negligible relative to the total resistance, and $(b)$ the inertia of the lines will be different to that of the anchor, such that the lines are assumed to become slack on impact with the seabed.

The frictional resistance term in equation (7) comprises friction on the follower, sleeve and flukes, whereas the bearing resistance term in equation (8) comprises bearing on the follower tip and at the base and upper end of the flukes (but not at the upper end of the follower, owing to the assumption that the cavity created by the passage of the advancing anchor remains open).

Soil strength depends on the rate at which it is sheared. This has been quantified in laboratory element tests reported by Vade \& Campenella (1977), Graham et al. (1983), Lefebvre \& Leboeuf (1987), Sheahan et al. (1996) and others, where a 10 to $20 \%$ increase in undrained shear strength was typically observed for every log cycle increase in shear strain rate. Similar dependence has been observed in shear vane tests (e.g. Biscontin \& Pestana, 2001; Peuchen $\&$ Mayne, 2007) and in variable rate penetrometer tests (Chung et al., 2006; Low et al., 2008; Lehane et al., 2009). This dependence of shear strength on shear strain rate is generally formulated using either semi-logarithmic or power functions (e.g. Biscontin \& Pestana, 2001), with the power function being more suited to the higher orders of magnitude variation in shear strain rate associated with dynamic installation problems. The power law function is expressed as

$$
R_{\mathrm{f}}=\left(\frac{\dot{\gamma}}{\dot{\gamma}_{\text {ref }}}\right)^{\beta}
$$

where $\beta$ is a strain rate parameter, $\dot{\gamma}$ is the strain rate and $\dot{\gamma}_{\text {ref }}$ is the reference strain rate associated with the reference value of undrained shear strength. During dynamic penetration the shear strain rate will vary through the soil body, but for shearing around an axially loaded cylindrical object such as the DEPLA it is reasonable to assume that at any given location, the operational strain rate will be proportional to the dimensionless velocity, $v / d_{\mathrm{f}}$, such that equation (10) may be replaced by

$$
R_{\mathrm{f}}=\left(n \frac{v / d_{\mathrm{f}}}{\dot{\gamma}_{\text {ref }}}\right)^{\beta} \text { or }\left[n \frac{v / d_{\mathrm{f}}}{(v / d)_{\mathrm{ref}}}\right]^{\beta}
$$

If the reference strength is determined from laboratory element tests, $\dot{\gamma}_{\text {ref }}$ in equation (11) is the strain rate employed in the element test, whereas if the reference strength is determined from a penetrometer test (such as the cone, T-bar or ball), $\dot{\gamma}_{\text {ref }}$ may be approximated by $(v / d)_{\text {ref }}$, where $v$ is the penetration velocity and $d$ is the diameter of the penetrometer. An important point to note is that in situ strengths determined from penetrometer tests are typically similar in magnitude to those determined in the laboratory (Low et al., 2010), despite a typical five orders of magnitude difference in the strain rates associated with the laboratory test (e.g. $\dot{\gamma}=1 \% / \mathrm{h}$ or $3 \times 10^{-6} \mathrm{~s}^{-1}$ ) compared with an average strain rate, $\dot{\gamma}=0 \cdot 18 \mathrm{~s}^{-1}$ associated with a $80 \mathrm{~mm}$ ball penetrometer penetrated at the standard $20 \mathrm{~mm} / \mathrm{s}$ (Randolph et al., 2007). This is due to the compensating effects of strain softening associated with the penetrometer strength and lower strain rate dependency at strain rates closer to the laboratory strain rate (Hossain \& Randolph, 2009). Hence, caution is required if equation (11) is adopted using a laboratory reference strain rate and strength, as the (intact) laboratory strength needs to be adjusted to reflect the strain softening associated with anchor installation and the strain rate dependency needs to be more moderate over the first few decades increase in strain rate.

The parameter $n$ in equation (11) is introduced to account for the greater rate effects reported for shaft resistance compared to tip resistance (Dayal et al., 1975; Chow et al., 2014; Steiner et al., 2014). It is quite probable that the higher rate effect for shaft resistance is due to the higher strain rate at the cylindrical shaft involving curved shear bands, which can be estimated to be about 20 to 40 times $v / d$ (for $\beta=0 \cdot 10$ and $0 \cdot 05$, respectively) using a rigorous energy approach maintaining equilibrium (Einav \& Randolph, 2006). Therefore, $n$ is taken as 1 for bearing resistance (Zhu \& Randolph, 2011) and as a function of $\beta$ (adapted from Einav \& Randolph (2006)) for estimating rate effects in frictional resistance according to

$$
n=2\left(\frac{n_{1}}{\beta}+n_{1}-2\right)
$$

where $n_{1}$ is taken as 1 for axial loading. 
The resulting acceleration data derived from measurements during penetration allow for an assessment of the suitability of the power law at the high strain rates associated with dynamic embedment. This can be achieved by rearranging equation (6), noting that $R_{\mathrm{f} \text {,frict }}=n^{\beta} R_{\mathrm{f} \text {, bear }}$ to give

$$
R_{\mathrm{f}, \text { bear }}=\frac{W_{\mathrm{s}}-m \mathrm{~d}^{2} s / \mathrm{d} t^{2}-F_{\mathrm{b}}-F_{\mathrm{d}}}{n^{\beta} F_{\text {frict }}+F_{\text {bear }}}
$$

Calculated values of $R_{\mathrm{f}}$ were obtained using $C_{\mathrm{d}}=0 \cdot 7$ as determined for this DEPLA geometry by Blake et al. (2015). Bearing resistance was calculated using $N=7 \cdot 5$ for the leading and trailing edges of the flukes (analogous to a deeply embedded strip footing) and $N=12$ for the follower tip (O'Loughlin et al., 2013), but not for the padeye, as the hole formed by the passage of the anchor was assumed to remain open during anchor penetration. This is appropriate, since remotely operated vehicle (ROV) video capture of the drop sites (see Fig. 7) showed an open crater and the dimensionless strength ratio, $s_{\mathrm{u}} / \gamma^{\prime} D_{\mathrm{s}}$, at the final follower embedment depth is sufficient to maintain an open cavity above the follower (O'Beirne et al., 2015). The open hole assumption requires that the soil buoyancy term, $F_{\mathrm{b}}$, is calculated using the volume of soil displaced at each time step. This will be the volume of the anchor submerged in water plus the volume of a hole with diameter $D_{\text {s }}$ extending from the top of the follower to the mudline.

The strain rate parameter was fixed at $\beta=0 \cdot 08$, which is typical of that measured in variable rate penetrometer testing (Low et al., 2008; Lehane et al., 2009) and approximates to a $20 \%$ change per log cycle change in strain rate, typical of that measured in laboratory testing as discussed earlier. The resulting values of $R_{\mathrm{f}}$ for friction and bearing are compared for two example tests in Fig. 12 with $R_{\mathrm{f}}$ formulated using the power law (equation (11)). The best agreement between the back-calculated $R_{\mathrm{f}}$ and that predicted by the power law was obtained using $\alpha=0 \cdot 22$ (test 12) and $0 \cdot 29$ (test 2). This is within the range established from cyclic piezoball remoulding tests, which gave $q_{\text {in }} / q_{\text {rem }}=0 \cdot 2$ to $0 \cdot 32$. Encouragingly, the power law is seen to satisfactorily quantify the correct amount and variation in strain rate dependence over the range of strain rates associated with dynamic penetration. However, Fig. 12 also plots the same $R_{\mathrm{f}}$ data against depth, revealing that there are other mechanisms during initial penetration that are not captured by equation (6). Nonetheless, Fig. 13 shows that the embedment model is seen to predict the experimental velocity profiles acceptably with bounds on $\alpha$ of 0.22 and 0.29 , similar to the bounds of $q_{\text {in }} / q_{\text {rem }}$ from the cyclic piezoball remoulding tests. More importantly, the final embedment depths are predicted accurately, which in turn increases the reliability of anchor capacity calculations. This is made clear by Fig. 14, which shows embedment test data for all the Firth of Clyde tests together with the corresponding embedment model predictions using an average $\alpha=0 \cdot 26$, presented in the 'total energy' format of Fig. 9. Also shown in Fig. 14 are predicted embedments using equation (2), which are seen to be in close agreement with those obtained using equation (6). The presentation format of Fig. 14 is appealing, as predicted anchor embedment can be presented on a single chart for a variety of model input parameters, making the model easily adoptable in design, as demonstrated in the following section.

\section{Design approach}

Figure 15 summarises embedment predictions for undrained strength gradients, $k=1,2$ and $3 \mathrm{kPa} / \mathrm{m}$ and interface friction ratios, $\alpha=0 \cdot 1,0 \cdot 2,0 \cdot 3,0 \cdot 4$ and $0 \cdot 5$ (corresponding to $S_{\mathrm{t}}=2$ to 10 ). The predictions were obtained by varying the impact velocity of a full-scale DEPLA with
$L_{\mathrm{f}}=9 \mathrm{~m}$. In this example $\beta=0 \cdot 08$, although additional charts may be generated for different strain rate parameters and indeed different strength gradients. Although total energy is normalised by the strength gradient, the predicted embedments still demonstrate some dependence on $k$, which is to be expected as the normalisation does not account for drag resistance, which will vary relative to the shear resistance as the strength gradient changes. Fig. 15 can be used to scale a DEPLA for a given design load as described in the following iterative approach.

(a) Assume an overall anchor scale to give the anchor mass, $m$, and geometry, allowing the anchor impact velocity to be calculated for a given anchor release height using a reduced form of equation (6): $m \mathrm{~d}^{2} s / \mathrm{d} t^{2}=W_{\mathrm{s}}-F_{\mathrm{d}}$ (i.e. removing the soil resistance terms).

(b) Assume an anchor tip embedment depth, $z_{\text {e,tip }}$ and calculate the total energy, $E_{\text {total }}=1 / 2 m v_{\mathrm{i}}^{2}+m^{\prime} \boldsymbol{g} z_{\mathrm{e} \text {,tip }}$ (equation (1)).

(c) Adjust the anchor scale and tip embedment until the combination of $z_{\mathrm{e}, \mathrm{tip}} / d_{\mathrm{eff}}$ and $E_{\mathrm{total}} / k d_{\mathrm{eff}}^{4}$ lies on the prediction line for the required $k$ and $\alpha$.

(d) Calculate the loss in plate anchor embedment due to keying (equation (3)) to determine the final plate embedment depth, $z_{\text {e,plate }}$

(e) Select a capacity factor from: $N_{\mathrm{c}}=14.9$ for $z_{\mathrm{e} \text {,plate }} / D \geq 2 \cdot 5$ and $N_{\mathrm{c}}$ using equation (5) for $z_{\mathrm{e} \text {,plate }} / D<2 \cdot 5$.

( $f$ ) Calculate the anchor capacity for the final plate embedment depth using the selected capacity factor and the submerged weight of the anchor in soil.

(g) Repeat steps $(a)-(f)$ until the anchor capacity is at least equal to the required design load.

Two example sites are now considered, making use of the design procedure outlined above, but limiting the anchor impact velocity to $80 \%$ of its terminal velocity to keep the anchor drop height within practical limits. The first site, referred to as site $\mathrm{A}$, has a zero mudline strength and a strength gradient, $k=1 \mathrm{kPa} / \mathrm{m}$ and the second site, referred to as site $\mathrm{B}$, also has a zero mudline strength but with a strength gradient $k=2 \mathrm{kPa} / \mathrm{m}$. Both sites have a sensitivity, $S_{\mathrm{t}}=5$, such that $\alpha=0 \cdot 2$. The factored design mooring line load is $5 \mathrm{MN}$. Applying the design approach described above results in an anchor for site A that has a follower length $L_{\mathrm{f}}=10 \cdot 3 \mathrm{~m}$, a plate diameter $D=4 \cdot 1 \mathrm{~m}$ and a total anchor mass, $m=75 \mathrm{t}$, of which the plate mass, $m_{\mathrm{p}}=33 \mathrm{t}$. Site $\mathrm{B}$ requires a smaller anchor, with a follower length $L_{\mathrm{f}}=8.8 \mathrm{~m}$, a plate diameter $D=3.5 \mathrm{~m}$ and a total anchor mass, $m=47 \mathrm{t}$, of which the plate mass, $m_{\mathrm{p}}=21 \mathrm{t}$. These results reinforce the observation made earlier in the paper, that embedments will be lower in stronger seabeds but that capacity will not be negatively affected. In fact, the results from the two example sites considered here infer that for the same anchor geometry and mass, the capacity may be higher for the stronger seabed, despite the lower embedment.

The above example includes a number of simplifying assumptions to demonstrate the merit of the design approach, but that would be refined for an actual design. These include the loss of embedment during keying, which has been conservatively calculated assuming vertical loading, whereas the loss of embedment will be lower for inclined loading (Gaudin et al., 2009; Song et al., 2009; Yu et al., 2009; Wang et al., 2011) and the adopted capacity factor which may need to be reduced for inclined loading at shallow embedment (Yu et al., 2011; Wang \& O'Loughlin, 2014).

\section{CONCLUSIONS}

As part of the development path towards qualification of the DEPLA, a series of centrifuge and reduced-scale field 

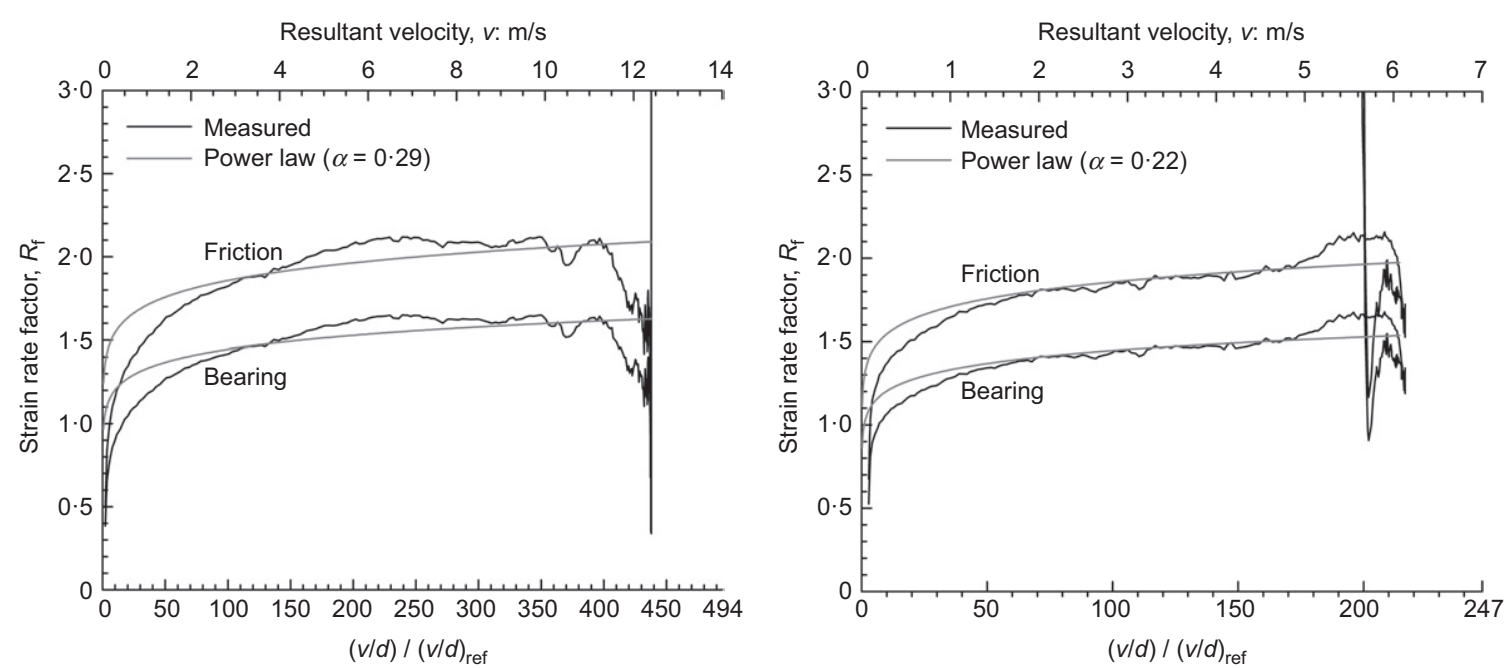

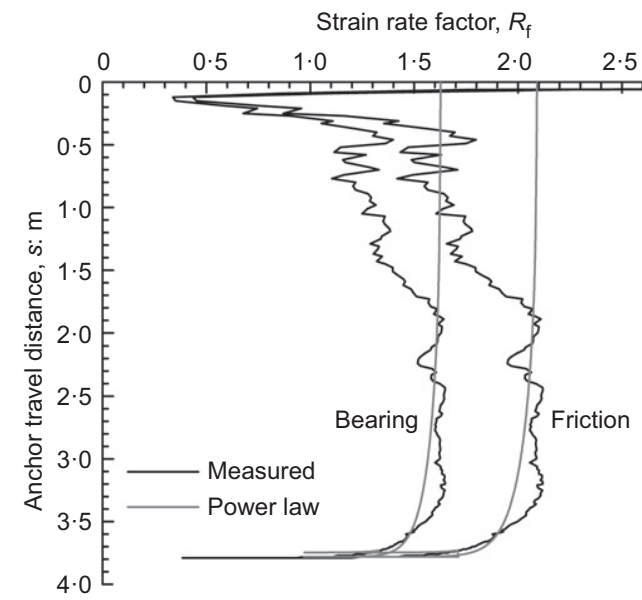

(a)

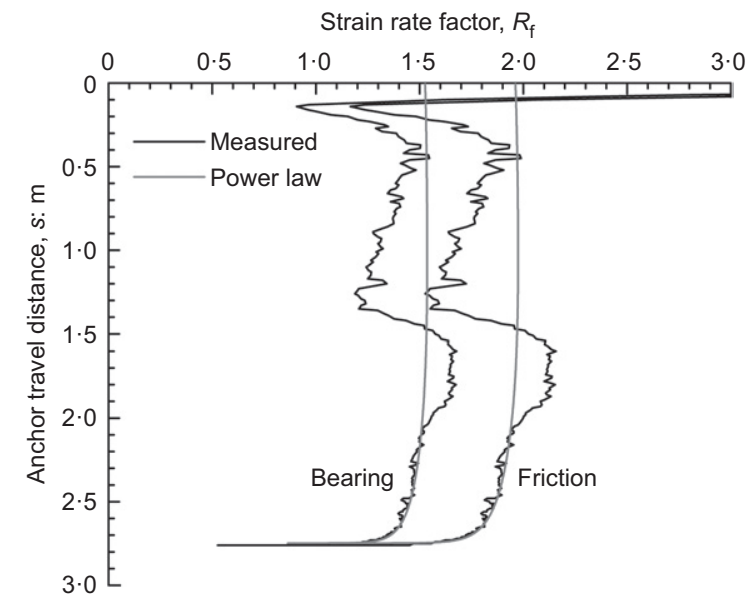

(b)

Fig. 12. Evaluation of the power law in quantifying strain rate dependency for dynamic installation problems: (a) test 2; (b) test 12

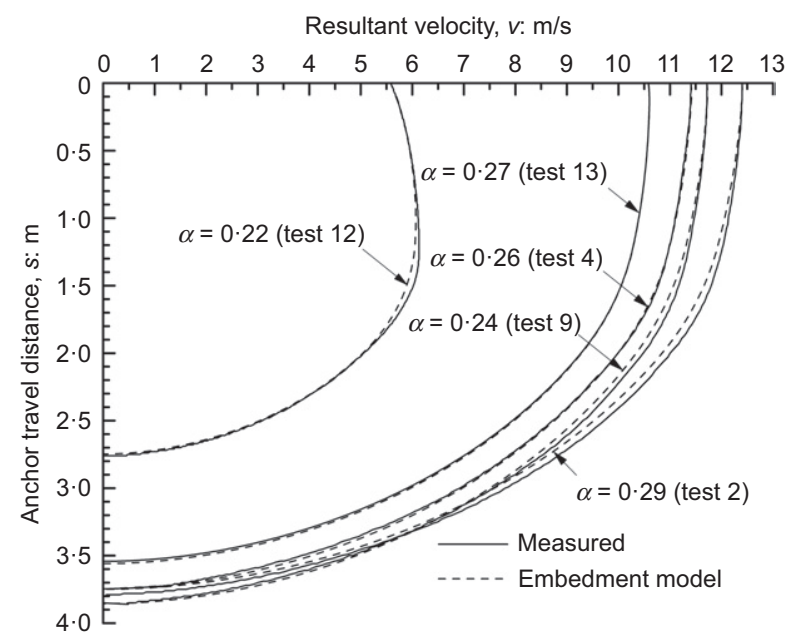

Fig. 13. Measured and predicted velocity profiles

trials, supplemented by analytical and numerical studies, has been undertaken. This paper considers the results from the final experimental campaign, in which field trials on a $1: 4 \cdot 5$ reduced-scale DEPLA were conducted in approximately $50 \mathrm{~m}$ water depth at a site off the west coast of Scotland. The data gathered in these trials have been considered in parallel with DEPLA field and centrifuge data from earlier in the experimental campaign to assess the merit of anchor

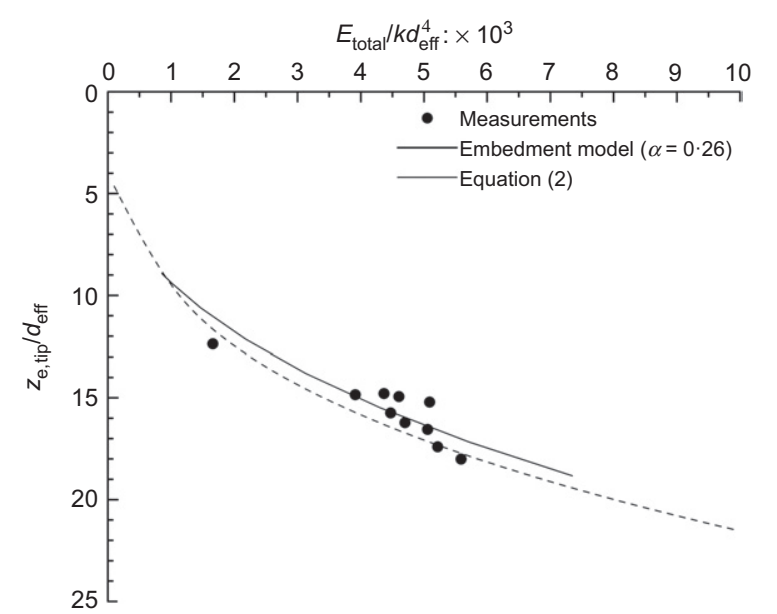

Fig. 14. Measured and predicted DEPLA follower tip embedments

embedment and capacity models. The anchor embedment model is cast in terms of drag resistance and strain rate enhanced shear resistance, the latter described using a power law with separate dependence for bearing and frictional resistance. Back-analysis of measured acceleration data during dynamic embedment indicated that the power law is capable of describing the strain rate dependence of undrained shear strength at the very high strain rates associated with the 


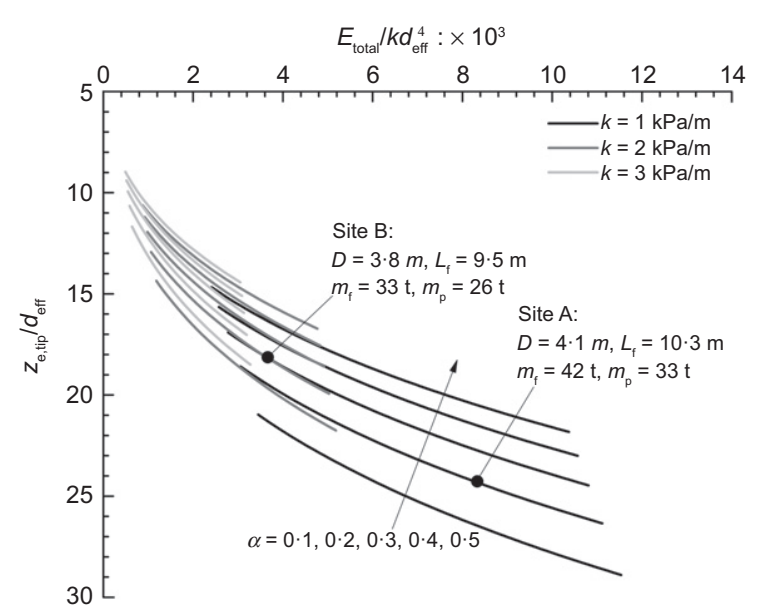

Fig. 15. DEPLA design chart for a range of seabed strength gradients and interface friction ratios

dynamic embedment process, although complexities associated with initial embedment (up to one anchor length) are not captured by the model. However, these shortcomings do not appear to unduly lessen the capability of the embedment model to predict the measured velocity profiles and, importantly, the final anchor embedment depth, which is a prerequisite for reliable calculation of anchor capacity.

Back-analysis of anchor capacity from each of the experimental campaigns was considered in terms of a dimensionless capacity factor and compared with corresponding numerically derived values. This comparison indicated the potential for soil tension to be lost at the underside of the anchor plate at shallow embedment, resulting in a lower capacity factor. At deep embedment, where the plate embedment is at least 2.5 times the diameter, the capacity factor reaches a limiting value that is in good agreement with that determined numerically.

Results from the embedment model were summarised in a design chart presented in terms of the total energy of the anchor at impact with the mudline for a range of seabed strength gradients and soil sensitivities. This was shown to be a useful design approach for scaling a DEPLA for a given mooring line load.

\section{ACKNOWLEDGEMENTS}

This work forms part of the activities of the Centre for Offshore Foundation Systems (COFS), currently supported as a node of the Australian Research Council Centre of Excellence for Geotechnical Science and Engineering and as a Centre of Excellence by the Lloyd's Register Foundation. The Lloyd's Register Foundation invests in science, engineering and technology for public benefit, worldwide. The authors also acknowledge the support of Enterprise Ireland, who funded the experimental work through their Commercialisation Fund Technology Development Programme.

\section{NOTATION}

$$
\begin{aligned}
A & \text { contact area } \\
A_{\mathrm{f}} & \text { frontal area of anchor } \\
C_{\mathrm{d}} & \text { drag coefficient } \\
c_{\mathrm{h}} & \text { horizontal coefficient of consolidation } \\
D & \text { plate diameter } \\
d & \text { penetrometer diameter } \\
d_{\mathrm{eff}} & \text { effective anchor diameter } \\
d_{\mathrm{f}} & \text { follower diameter }
\end{aligned}
$$

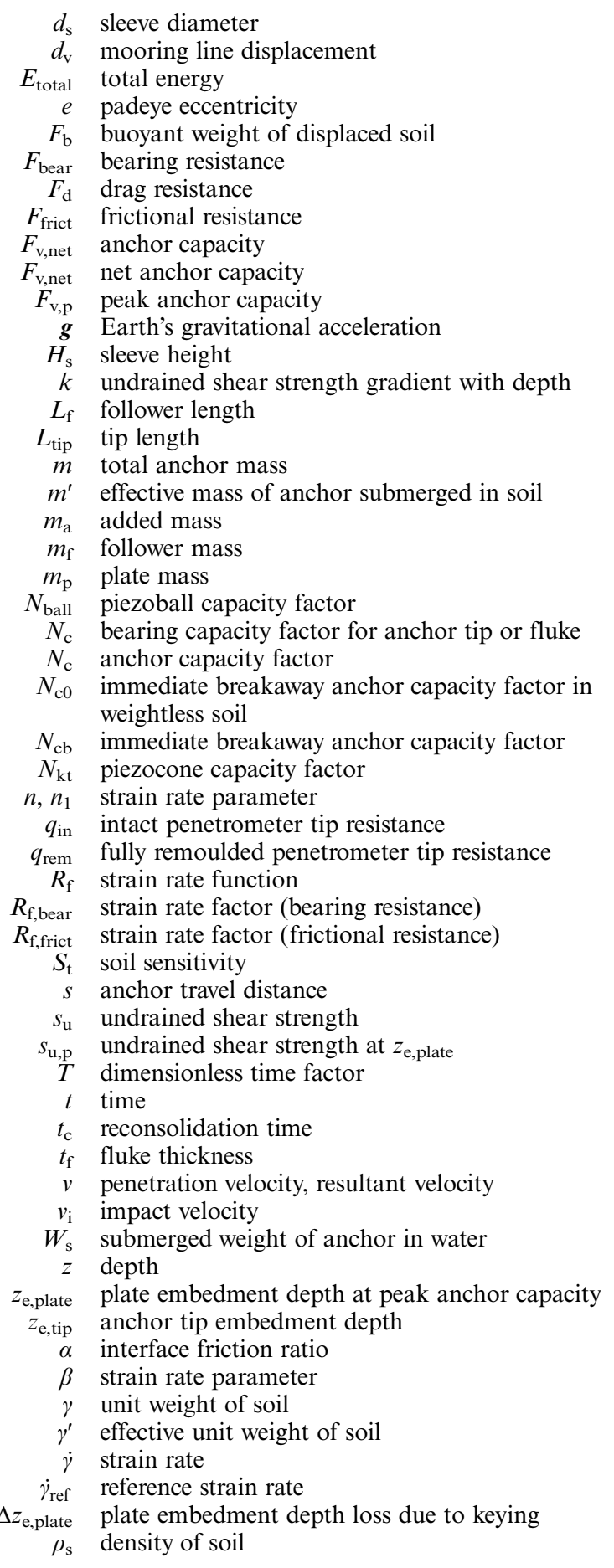

\section{REFERENCES}

Aubeny, C. P. \& Shi, H. (2006). Interpretation of impact penetration measurements in soft clays. ASCE J. Geotech. Geoenviron. Engng 132, No. 6, 770-777.

Audibert, J. M. E., Movant, M. N., Won, J. Y. \& Gilbert, R. B. (2006). Torpedo piles: laboratory and field research. Proceedings of the 16th international offshore and polar engineering conference, San Francisco, CA, USA, pp. 135-142.

Beard, R. M. (1981). A penetrometer for deep ocean seafloor exploration. In Oceans 81: the ocean ... an international workplace, pp. 668-673. New York, NY, USA: Institute of Electrical and Electronics Engineers.

Biscontin, G. \& Pestana, J. M. (2001). Influence of peripheral velocity on vane shear strength of an artificial clay. ASTM Geotech. Testing J. 24, No. 4, 423-429.

Blake, A. P. \& O’Loughlin, C. D. (2015). Installation of dynamically embedded plate anchors as assessed through field tests. Can. Geotech. J. 52, No. 9, 1270-1282. 
Blake, A. P., O’Loughlin, C. D. \& Gaudin, C. (2015). Capacity of dynamically embedded plate anchors as assessed through field tests. Can. Geotech. J. 52, No. 1, 87-95.

Blake, A. P., O'Loughlin, C. D., Morton, J. P., O'Beirne, C., Gaudin, C. \& White, D. J. (2016). In-situ measurement of the dynamic penetration of free-fall projectiles in soft soils using a low cost inertial measurement unit. ASTM Geotech. Testing J. 39, No. 2, 235-251.

Boukpeti, N., White, D. J. \& Randolph, M. F. (2012). Analytical modelling of the steady flow of a submarine slide and consequent loading on a pipeline. Géotechnique 62, No. 2, 137-146, http://dx.doi.org/10.1680/geot.10.P.001.

Brandão, F. E. N., Henriques, C. C. D., Araújo, J. B., Ferreira, O. C. G. \& Amaral, C. D. S. (2006). Albacora Leste field development: FPSO P-50 mooring system concept and installation. Proceedings of the offshore technology conference, Houston, TX, USA, paper OTC 18243.

Cassidy, M. J., Gaudin, C., Randolph, M. F., Wong, P. C., Wang, D. \& Tian, Y. (2012). A plasticity model to assess the keying of plate anchors. Géotechnique 62, No. 9, 825-836, http://dx.doi. org/10.1680/geot.12.OG.009.

Chow, S. H., O'Loughlin, C. D. \& Randolph, M. F. (2014). Soil strength estimation and pore pressure dissipation for free-fall piezocone in clay. Géotechnique 64, No. 10, 817-827, http://dx. doi.org/10.1680/geot.14.P.107.

Chung, S. F., Randolph, M. F. \& Schneider, J. A. (2006). Effect of penetration rate on penetrometer resistance in clay. $A S C E$ J. Geotech. Geoenviron. Engng 132, No. 9, 1188-1196.

Das, B. M. \& Singh, G. (1994). Uplift capacity of plate anchor in clay. Proceedings of the 4th international offshore and polar engineering conference, Osaka, Japan, pp. 436-442.

Dayal, U., Allen, J. \& Jones, J. (1975). Use of an impact penetrometer for the evaluation of the in-situ strength of marine sediments. Mar. Georesources Geotechnol. 1, No. 2, 73-89.

Einav, I. \& Randolph, M. F. (2006). Effect of strain rate on mobilised strength and thickness of curved shear bands. Géotechnique 56, No. 7, 501-504, http://dx.doi.org/10.1680/ geot.2006.56.7.501.

Gaudin, C., O’Loughlin, C. D., Randolph, M. F. \& Lowmass, A. (2006). Influence of the installation process on the performance of suction embedded plate anchors. Géotechnique 56, No. 6, 389-391, http://dx.doi.org/10.1680/geot.2006.56.6.381.

Gaudin, C., Tham, K. H. \& Ouahsine, S. (2009). Keying of plate anchors in NC clay under inclined loading. Int. J. Offshore Polar Engng 19, No. 2, 1-8.

Graham, J., Crooks, J. H. A. \& Bell, A. L. (1983). Time effects on the stress-strain behaviour of natural soft clays. Géotechnique 33, No. 3, 327-340, http://dx.doi.org/10.1680/geot.1983.33. 3.327 .

Han, C., Wang, D., Gaudin, C., O’Loughlin, C. D. \& Cassidy, M. J. (2016). Behaviour of vertically loaded plate anchors under sustained uplift. Géotechnique, http://dx.doi.org/10.1680/jgeot. 15.P.232.

Hossain, M. \& Randolph, M. F. (2009). Effect of strain rate and strain softening on the penetration resistance of spudcan foundations on clay. Int. J. Geomech. 9, No. 3, 122-132.

Lefebvre, G. \& Leboeuf, D. (1987). Rate effects and cyclic loading of sensitive clays. ASCE J. Geotech. Geoenviron. Engng 113, No. 5 , 476-489.

Lehane, B. M., O'Loughlin, C. D., Gaudin, C. \& Randolph, M. F. (2009). Rate effects on penetrometer resistance in kaolin. Géotechnique 59, No. 1, 41-52, http://dx.doi.org/10.1680/geot. 2007.00072.

Levacher, D. (1985). Penetrometre a chute libre: impact et penetration dans des argiles reconstituees. Can. Geotech. J. 22, No. 1, 129-135 (in French).

Lieng, J. T., Tjelta, T. I. \& Skaugset, K. (2010). Installation of two prototype deep penetrating anchors at the Gjøa field in the North Sea. Proceedings of the 2010 offshore technology conference, Houston, TX, USA, paper OTC 20758.

Low, H. E., Randolph, M. F., DeJong, J. T. \& Yafrate, N. J. (2008). Variable rate full-flow penetration tests in intact and remoulded soil. Proceedings of the 3rd international conference on site characterization, Taipei, Taiwan, pp. 1087-1092.

Low, H. E., Lunne, T., Andersen, K. H., Sjursen, M. A., Li, X. \& Randolph, M. F. (2010). Estimation of intact and remoulded undrained shear strengths from penetration tests in soft clays. Géotechnique 60, No. 11, 843-859, http://dx.doi.org/10.1680/ geot.9.P.017.

Martin, C. M. \& Randolph, M. F. (2001). Applications of the lower and upper bound theorems of plasticity to collapse of circular foundations. Proceedings of the 10th international conference of the International Association of Computational Methods and Advances in Geomechanics (IACMAG), Tucson, AZ, USA, vol. 2, pp. 1417-1428.

Merifield, R. S., Sloan, S. W. \& Yu, H. S. (2001). Stability of plate anchors in undrained clay. Géotechnique 51, No. 2, 141-153, http://dx.doi.org/10.1680/geot.2001.51.2.141.

Merifield, R. S., Lyamin, A. V., Sloan, S. W. \& Yu, H. S. (2003). Three-dimensional lower bound solutions for stability of plate anchors in clay. ASCE J. Geotech. Geoenviron. Engng 129 No. 3, 243-253.

O'Beirne, C., O'Loughlin, C. D. \& Gaudin, C. (2015). Soil response in the wake of dynamically installed projectiles. Géotechnique Lett. 5, No. 3, 153-160, http://dx.doi.org/10.1680/jgele.15. 00055 .

O'Loughlin, C. D., Randolph, M. F. \& Richardson, M. (2004). Experimental and theoretical studies of Deep Penetrating Anchors. Proceedings of the offshore technology conference, Houston, TX, USA, paper OTC 16841.

O'Loughlin, C. D., Lowmass, A., Gaudin, C. \& Randolph, M. F. (2006). Physical modelling to assess keying characteristics of plate anchors. Proceedings of the 6th international conference on physical modelling in geotechnics, Hong Kong, vol. 1, pp. 659-665.

O’Loughlin, C. D., Richardson, M. D. \& Randolph, M. F. (2009). Centrifuge tests on dynamically installed anchors. Proceeding of the 28th international conference on offshore mechanics and arctic engineering, Honolulu, HI, USA, paper number OMAE2009-80238.

O'Loughlin, C. D., Richardson, M., Randolph, M. F. \& Gaudin, C. (2013). Penetration of dynamically installed anchors in clay. Géotechnique 63, No. 11, 909-919, http://dx.doi.org/10.1680/ geot.11.P.137.

O’Loughlin, C. D., Blake, A., Richardson, M. D., Randolph, M. F. \& Gaudin, C. (2014a). Installation and capacity of dynamically embedded plate anchors as assessed through centrifuge tests. Ocean Engng 88, 204-213.

O’Loughlin, C. D., Nazem, M., Chow, S. H., Randolph, M. F., Gaudin, C. \& White, D. J. (2014b). Dynamic embedment of projectiles in clay. Aust. Geomech. J. 49, No. 4, 133-146.

O'Loughlin, C. D., White, D. J. \& Stanier, S. (2015). Novel Anchoring Solutions for FLNG - opportunities driven by scale. Proceedings of the offshore technology conference, Houston, TX, USA, paper OTC-26032.

Peuchen, J. \& Mayne, P. (2007). Rate effects in vane shear testing. Proceedings of the 6th international conference on offshore site investigation and geotechnics, London, UK, pp. 187-194.

Randolph, M. F. \& White, D. J. (2012). Interaction forces between pipelines and submarine slides - a geotechnical viewpoint. Ocean Engng 48, 32-37.

Randolph, M. F., Low, H. E. \& Zhou, H. (2007). Keynote lecture: in situ testing for design of pipeline and anchoring systems. Proceedings of the 6th international conference on offshore site investigation and geotechnics, London, UK, pp. 251-262.

Sahdi, F., Gaudin, C., White, D. J., Boylan, N. \& Randolph, M. F. (2014). Centrifuge modelling of active slide - pipeline loading in soft clay. Géotechnique 64, No. 1, 16-27, http://dx.doi.org/ 10.1680/geot.12.P.191.

Sheahan, T., Ladd, C. \& Germaine, J. (1996). Rate-dependent undrained shear behavior of saturated clay. ASCE J. Geotech. Engng 122, No. 2, 99-108.

Shelton, J. T., Nie, C. \& Shuler, D. (2011). Installation penetration of gravity installed plate anchors - laboratory study results and field history data. Proceedings of the offshore technology conference, Houston, TX, USA, paper OTC 22502.

Song, Z., Hu, Y. \& Randolph, M. F. (2008). Numerical simulation of vertical pullout of plate anchors in clay. ASCE J. Geotech. Geoenviron. Engng 134, No. 6, 866-875.

Song, Z., Hu, Y., O'Loughlin, C. D. \& Randolph, M. F. (2009). Loss in anchor embedment during plate anchor keying in 
clay. ASCE J. Geotech. Geoenviron. Engng 135, No. 10, 1475-1485.

Steiner, A., Kopf, A. J., L'Heureux, J. S., Kreiter, S., Stegmann, S., Haflidason, H. \& Moerz, T. (2014). In situ dynamic piezocone penetrometer tests in natural clayey soils-a reappraisal of strain-rate corrections. Can. Geotech. J. 51, No. 3, 272-288.

True, D. G. (1976). Undrained vertical penetration into ocean bottom soils. PhD thesis, University of California, Berkeley, CA, USA.

Vade, Y. P. \& Campenella, R. G. (1977). Time-dependent behaviour of undisturbed clay. ASCE J. Geotech. Geoenviron. Engng 103, No. GT7, 693-709.

Wang, D. \& O'Loughlin, C. D. (2014). Numerical study of pull-out capacities of dynamically embedded plate anchors. Can. Geotech. J. 51, No. 11, 1263-1272.

Wang, D., Hu, Y. \& Randolph, M. F. (2010). Three-dimensional large deformation finite-element analysis of plate anchors in uniform clay. ASCE J. Geotech. Geoenviron. Engng 136, No. 2, 355-365.

Wang, D., Hu, Y. \& Randolph, M. F. (2011). Keying of rectangular plate anchors in normally consolidated clays. ASCE J. Geotech. Geoenviron. Engng 137, No. 12, 1244-1253.

Yang, M., Aubeny, C. \& Murff, J. (2012). Behavior of suction embedded plate anchors during keying process. ASCE J. Geotech. Geoenviron. Engng 138, No. 2, 174-183.

Yu, L., Liu, J., Kong, X. J. \& Hu, Y. (2009). Three-dimensional numerical analysis of the keying of vertically installed plate anchors in clay. Comput. Geotech. 36, No. 4, 558-567.

Yu, L., Liu, J., Kong, X. J. \& Hu, Y. (2011). Numerical study on plate anchor stability in clay. Géotechnique 61, No. 3, 235-246, http://dx.doi.org/10.1680/geot.8.P.071.

Zhu, H. \& Randolph, M. F. (2011). Numerical analysis of a cylinder moving through rate-dependent soils. Ocean Engng 38, No. 7, 943-953. 